\title{
AC 2011-2281: MAKING A DIFFERENCE: HOW TO RECRUIT MORE COMMUNITY COLLEGE WOMEN AND UNDERREPRESENTED MI- NORITY STUDENTS INTO ENGINEERING AND COMPUTER SCIENCE
}

\section{Mary R. Anderson-Rowland, Arizona State University}

MARY R.ANDERSON-ROWLAND is the PI of an NSF STEP grant to work with five non-metropolitan community colleges to produce more engineers, especially female and underrepresented minority engineers. She also directs three academic scholarship programs, including one for transfer students. An Associate Professor in Computing, Informatics, and Systems Design Engineering, she was the Associate Dean of Student affairs in the Ira a. Fulton School of Engineering at ASU from 1993-2004. She was named a top 5\% engineering teacher for 2009-2010. She received the WEPAN Engineering Educator Award 2009, ASEE Minorities Award 2006, the SHPE Educator of the Year 2005, and the National Engineering Award in 2003, the highest honor given by AAES. In 2002 she was named the Distinguished Engineering Educator by the Society of Women Engineers. Her awards are based on her mentoring of students, especially women and underrepresented minority students, and her research in the areas of recruitment and retention. A SWE and ASEE Fellow, she is a frequent speaker on career opportunities and diversity in engineering.

\section{Ms. Anita Grierson, Arizona State University}

Anita Grierson, AZ State University ANITA E. GRIERSON is the Director of the METS Center in the Ira A. Fulton School of Engineering at ASU. She is now in her third year of guiding the activities of the METS Center and overseeing its staff of primarily transfer students. Ms. Grierson has over 10 years corporate experience in Program Management, Business Development, and Biomechanical Engineering, with products as diverse as air bag systems for helicopters, body armor, and orthopedic implants. She received her Bachelors Degree in Mechanical Engineering from the University of Michigan in 1990, her Masters degree in Mechanical Engineering from Northwestern University in 1994, and a Masters in Business Administration from Arizona State University in 2000. 


\title{
Making a Difference: How to Recruit More Community College Women and Underrepresented Minority Students Into Engineering and Computer Science
}

\begin{abstract}
Through an NSF STEP grant (\# 0856834), a Research I university is collaborating with five nonmetropolitan community colleges, some of which are minority institutions, to encourage more students to study engineering and computer science, to make their transfer easier, and to support the students after they have transferred. The first step is to get the high school or community college students' attention and to have them consider engineering and computer science. Most of these students have never met an engineer and have never been visited by someone from a university. Something more is needed than just "talking engineering" to students who are invited to come and to listen to some university folks. To get the community college students' attention, a captive audience (meeting with a mathematics or science class) and "intrusive advising" is needed and effective.

This paper describes the impact of information and recruitment visits by university professors, staff, and students on high school and community college students at non-metropolitan community colle ges and their visits to the university campus. "Intrusive advising" will be discussed and illustrated. Of particular interest will be the female and underrepresented minority students who are reached through this program.
\end{abstract}

\section{Introduction}

Although there are many reasons to choose to go to a community college, economics usually being a large factor, many students make this choice because they don't know in which field they want to major. Research has shown that many students do not choose engineering or computer science as a major until after they are at the community college. Students who come from rural (non-metropolitan) areas often choose a community college because it is close and, due to a lack of diverse role models, may not know which career pathway to choose.

"Do you have any idea of the impact that you are making on these students by talking to them about career planning and a career in engineering or computer science?" This question was recently asked of university professors who had just visited a non-metropolitan community college where students grow up and are familiar with only two or three careers available in their area. Earlier we had tried to talk to community college students by holding a meeting and inviting the students and their parents to come and hear about 'exciting opportunities' in engineering and computer science. This did not work well. Very few people came. We assumed that if students and their parents knew this information was available they would come to receive it. We were wrong. In many cases, the student doesn't realize that they need the help 
that is available with advising. Proactive steps must be taken to get the information to the student.

'Intrusive Advising, defined by the work of Robert Glennen, takes developmental advising theory one step further. Intrusive advising is proactive. Programs utilizing intrusive advising build structures that incorporate intervention strategies mandating advising contacts for students who otherwise might not seek advising." 1 Links to many articles about "intrusive advising" can be found at this source. Sharon Holmes, Iowa State University, describes "Intrusive Advising" as a model for retention. She points out that "many student support programs are designed based upon the assumption that students will self-identity academic and developmental needs and seek assistance. Some minority students and entering first-year college students have not established behavioral patterns that would motivate them to seek the assistance of these services. The Intrusive Advising model is valuable because it assumes that some students will not take the initiative in resolving their academic concerns, therefore, assigned counselors operate intrusively. $" 2$

Many community college students are in this situation. They are much like first-year college students. They are not sure of what they want to study, what they want to do for a career, what they want to do next. In order to get the community college student thinking about these things, he or she needs to be asked point blank about them. This impact can be made by "intrusive advising". New visions and information are "forced" onto the student and the student is "forced" to consider what is presented. This advising is rather "intrusive", but it is done with passion, conviction, and data. "Intrusive advising" can be very effective on high school and community college (CC) students when they are asked to consider what type of career they would like to have and then presented with the creative, people-helping, challenging, innovative, exciting careers that are available in engineering and computer science. For the first time engineering and computer science are on the radar for these students. The students are further presented with what engineers do and the $21^{\text {st }}$ Century challenges that engineers now face. Once engineering is on the radar for a CC student, it is important that the student can envision themselves as an engineering student at a four-year college. There are many fears and uncertainties that must be addressed for most potential transfers.

We have learned that in doing intrusive advising, "You've got to know the territory!" It will be up to you to anticipate the questions and myths that students might have about engineering. For example, a student recently shared that he had wanted to be an engineer for a long time, but he had now changed his major to one that leads directly to working in a lab. He wanted to do research and someone told him that engineers don't do research, so he had found this science program that promised jobs in a lab.

Based on collaborative work with local community colleges, the Ira A. Fulton School of Engineering received an NSF grant (\# 0836050) in Fall 2008 to explore the feasibility of a collaborative of three non- metropolitan community colleges and a large four-year public research university and to continue support for a METS (Motivated Engineering Transfer Students) Center at ASU as a home base of support for engineering transfer students. After a successful teaming of liaisons from each school, a second larger N SF STEP grant (\#0856834) was obtained in Fall 2009 to continue this work and to add two additional non-metropolitan 
community colleges to the mix. This program is called METSTEP. Based on a successful third year review, this grant is for five years and also supports the METS Center, as well as some \$4K scholarships for students from the five targeted schools and additional $\$ 300$ scholarships for transfer students who register, attend, and do the assignments on time for a one credit Academic Success Class. Much of this work has already been documented. ${ }^{3-9}$. The support for engineering transfer students at ASU is further enhanced through an S-STEM Academic Success Program (NSF grant \# 0728695).

\section{Community College Visits by ASU}

There is nothing more effective than a meeting face to face when a university person wants to make contact with a community college student. For these non-metropolitan community colleges, representatives from a university had not visited their campus previously. Although the travel time to four of the five schools is over three hours each way, the PI, co-PI, and Program Director on the METSTEP project feel that the time is well spent. We learned early that just having a meeting and expecting students or students and their parents to come, does not work well. The most effective and efficient use of time is to talk to the captive audience in a classroom.

There are two aspects of these visits. First, administrators at the community college need to get the permission of instructors to give up class time and to make a schedule that is efficient, allowing the college visitors the opportunity to see as many students as possible. It may take a couple of visits to the college in order for the mathematics and science teachers to realize the value of giving up some of their classroom time to university visitors. It is good for the university visitor to point out the important role that community college instructors play in teaching math and science at the $\mathrm{CC}$ level. At the same time, it is good to compliment the students in pre-engineering type courses that they have chosen some of the 'harder' courses to take. Students are interested to know that studies show that people who have a basic knowledge of mathematics and the time value of money and interest, in general have a much higher income than people who don't. The engineering presentation can help the students connect that what they are studying now will have value later in their engineering studies.

The date of the visit is carefully planned between the ASU and CC participants. For the ASU visitors, this is usually a long day, from 6:00 am to after 10:00pm. Second, the ASU engineering presentation needs to be properly geared to the particular class. For classes of dual enrolled high school students, the message needs to be basic and well founded in positive messaging. ${ }^{10}$ Assumptions on college need to be limited since the question, 'Is it better to get an Associate's Degree or a Bachelor's Degree?" may pop-up. A good way to get the students' interest is to ask them about their career plans. First, what type of a career would they like? Usually the answer to this question will be that the career is interesting, challenging, and provides a very good income. This is a very good segway into a discussion of a career in engineering. Exciting pictures of many different types of engineering are interesting to students. Slides, videos, and a discussion of the major technological challenges the world faces usually opens up young minds. Often we will get the response: "My Dad is a Mechanical Engineer. I didn't know there were so many different kinds of engineering!" We urge the students to get at least a 3.0 average, since this is the minimum requirement for engineering at ASU. For students within a year of 
transferring, we emphasize important dates in order to take part in Early Registration and to meet scholarship deadlines. We urge the students to talk to the academic advisor at ASU in their major, to make sure that they are taking the correct courses. Sometimes taking a course or two during the summer before transfer to ASU can save the student a full semester due to prerequisite courses. All courses offered by the three Arizona Universities and Arizona's twenty-one community colleges are already recognized through a complete articulation agreement and course equivalency guide. ASU's Vice Provost for Transfer Partnerships is leading an effort to have "METS Pathways" available for potential transfer students: a curriculum road map that spans both the particular CC and a particular engineering major at ASU to empower the transfer students to be taking the correct courses in an efficient manner.

The students are given resource materials and website locations where they can find more information. They are also offered the opportunity to have a transfer student as a mentor at ASU in their major. This opportunity is not well used. Usually the CC student does not respond to emails even if a mentor is requested. However, the students now know someone at the university and will often follow up with questions by contacting the university visitors by email or phone.

\section{Community College Visits to ASU}

For many students, this is their first visit to the ASU campus. Since ASU is now the largest university in the nation and the Tempe Campus, where engineering and the METS Center are located, is the largest single campus in the nation. Therefore, to drive in by van or car from a non-metropolitan area of the state to this campus is intimidating in itself. If a student can determine where to park and how to get to the part of the campus with engineering and the METS Center, half of the battle is won. Most students walking on the ASU campus find it to be very pleasant and inviting. A short tour on campus is a great recruitment tool, however the Community College visits to ASU are centered around the METS Center and its staff.

The potential transfer student is aware that they are leaving familiar confines with free parking, small classrooms, friendly instructors who know them, and the students with whom they have taken several math and science classes. The METS Center shows this student that there is a home base for them at ASU. This Center is filled with computers and free printing, a place to study and network, a place for a study group to meet, as well as a place to eat lunch with a refrigerator and microwave for convenience. The Center Director and the Center staff, friendly and willing to help, serve as informal counselors and resources to transfer students.

During the ASU Visit, the community college students are given help and advice on registration and advising, financial aid, career services available for them, internships, research programs, deadlines, and are able to go on a lab tour. Some visits include a presentation on the "Guaranteed 4.0 Plan" developed by Donna O. Johnson" on learning skills that if followed completely can lead to a 4.0 GPA average. Some students have taken advantage of this learning system and put it into effect immed iately at their $\mathrm{CC}$ with excellent results. During the visit, if possible, the visiting student is able to dialogue with one or more role models, a transfer student in their intended major and, if possible, from their college and with the same gender and ethnicity if the student is underrepresented. The role models help give the potential transfer student encouragement that they, too, can succeed in engineering at ASU. The visitors are able 
to ask questions and sign up for a mentor, if they wish. The mentoring is then done through emails. Lunch and snacks are served in the METS Center.

The numbers of students from the target school for Fall 2010 is given in Table I. Recall that all of the students except those from Central Arizona had to travel at least three hours each way to make the trip. CC faculty accompany the students. The goal is to have a group of students from each of these schools visit ASU once each semester. Sometimes several schools visit on the same day; sometimes just one school will come for a visit on a particular day.

\begin{tabular}{|l|l|l|l|}
\hline School & $\begin{array}{l}\text { Number of students } \\
\text { enrolled }^{*}\end{array}$ & Ethnicity & Gender \\
\hline Arizona Western & 7 & $\begin{array}{l}\text { 5 Hispanic, 1 } \\
\text { Caucasian, 1 Asian }\end{array}$ & 5 Male, 2 Female \\
\hline Central Arizona & 17 & $\begin{array}{l}\text { 7 Hispanic, 2 Asian, 4 } \\
\text { Caucasian, 4 Not } \\
\text { Reported }\end{array}$ & 10 Male, 7 Female \\
\hline Cochise & 11 & $\begin{array}{l}\text { 4 Hispanic, 2 Asian, 3 } \\
\text { Caucasian, 1 Native } \\
\text { American, 1 Not } \\
\text { Reported }\end{array}$ & 6 Male, 5 Female \\
\hline Eastern Arizona & 9 & $\begin{array}{l}\text { 2 Hispanic, 7 } \\
\text { Caucasian }\end{array}$ & All Male \\
\hline Mohave & 9 & $\begin{array}{l}\text { 1 Hispanic, 6 } \\
\text { Caucasian, 2 Not } \\
\text { Reported }\end{array}$ & 7 Male, 2 Female \\
\hline Totals & 53 & & 37 Male, 16 Female \\
\hline
\end{tabular}

Table I. Transfer Orientation Fall 2010

*Some late arriving students did not fill out enrollment forms

Since the goal of bringing in more underrepresented (women and underrepresented ethnic minority) students includes retaining and graduating them, the METS Center operates as a retention support for the METS TEP program.

\section{The METS Center}

The METS Center at ASU is a student center serving primarily engineering transfer students from our Arizona Community Colleges. In the last three years we have focused on building a center that provides more than the free printing, computers and refrigerator that are the initial draw for students. Our student workers and director provide transfer students with formal and informal mentoring and tutoring students as well as provide a welcoming atmosphere. We have reached out to our transfer student community in particular by hiring student workers who are in leadership positions in organizations such as Society for Hispanic Professional Engineers (SHPE) and Mexican American Engineers and Scientists (MAES) and in technical project teams such as SAE's Baja Car and ASCE's Concrete Canoe team. This provides a double benefit of increasing the visibility of the METS Center among the general student population as well as encouraging our transfer students to get involved in campus organizations. 
All students who use the METS Center are required to enroll. Our enrollment has increased from 77 students in the Fall of 2006, to 126 students in the Fall of 2008, to 183 students this past Fall 2010. Over this same time period, usage of the center has increased from an average of 14 students a day in 2006, to 24 students per day in 2008 to 44 students per day in 2010. The increase in student use of the center can be attributed not only to our focus on mentoring and networking, but also to an increased awareness of the METS Center from a new transfer orientation sponsored by the Engineering School. With 44 students per day at the Center, we often reached capacity with quiet seating and students computers fully occupied. Laptops donated from Motorola and the addition of student study desks from elsewhere in the University will hopefully allow us to continue to expand our services to reach even more transfer students.

Of the students who use the METS Center, $69 \%$ of the students are actually transfer students. Students, particularly those from minority engineering scholarship programs or those who participate in study groups with our transfer students are invited to also join the METS Center. Of our enrollees, 62 or $34 \%$ are female and 21 students are from our grant Community Colleges. Our METS students are 36\% Hispanic, 32\% Caucasian, 18\% Asian, 6\% African American, and 4\% Native American. The larger than expected percentage of Asian students is due to our invitation to students in an exchange program from China to use the Center. There are 12 of these students enrolled in our METS program. The average age for the METS student is 23 years old while there are 19 students over the age of 30 years old. Of the students from our grant Community Colleges, $82 \%$ are Hispanic with the rest Caucasian, $18 \%$ are female, and the average age is 22 . On an interesting note, students were queried on the enrollment form about their interest in graduate school. Of the 183 enrollees, 113 or $62 \%$ indicated that they want to attend Graduate School after graduation.

\section{Lessons Learned and Outcomes}

Although classrooms are the ideal way to talk to students about a possible engineering career, we found that, at first, instructors were reluctant to give up more than about 10 minutes in a classroom. The instructors felt that they already had more material to cover than there was time for, and therefore did not want to give up much time. A good way to make this situation a "winwin" is for the university visitors to impress upon the students that their choice to take a math or science class is a very wise choice. Data can be shown that the income expectation from someone who has taken more math is incredible. The life-time salaries of people can be compared who do not have a high school degree, have a high school degree, have an Associate's degree, have a Bachelor's degree, have a Master's degree, and have a PhD, as well as those who have professional skills. Although money is not a reason to choose a career, if a career is chosen because it is interesting and challenging, a good salary is nice.

As you are complimenting the students on taking math and science classes, don't forget to compliment the instructors who are doing the important job of teaching the math, science, and engineering. When instructors realize that you are encouraging students to take more math and science and to understand how important it is, they will soon be giving you a full class time and have found a way to teach some of their material in an alternative form. 
Another good format for recruiting engineering students to the community college is to have a university team present at a high school event at the community college.

In order to help the students think more broadly, it is an interesting exercise to ask the students what they plan to do as a career. "Intrusive advising" can be used here for information and effect. When a student says a pharmacist, you might challenge the student to also check out Chemical Engineering: it might be more interesting to design drugs than to prescribe them. Based on TV ads, young women may have chosen the area of physical therapy. The training is short and the salaries presumably good; however, you might challenge them to think ahead that physical therapy is a tough physical job and most women over 35 will be looking for something else. The "people helping" aspect of engineering is very important to emphasize in groups of all students, but especially underrepresented students.

We are fortunate to have dedicated and passionate people on this project. It has been a pleasurable experience working together to help students. In all of the university presentations and visits, if a transfer student, especially a woman or minority student from that particular college, presents to the students, then the presentation will be the most passionate and effective. We have learned that it is very exciting for a student to be able to come back to his old school and to tell others about his or her experiences as a university student. It is important for a CC student to hear, "Just two years ago, I was sitting in this classroom, and now I am about to graduate and I will be going on to graduate school in engineering. I would like to describe a couple of research projects on which I have worked." This message is especially important since we have learned that many children who grow up in non-metropolitan areas have little idea of the availability of jobs and careers outside of what they see in their small home town. It is very important to catch their imagination as early as possible so they will want to learn subjects that can lead them to exciting careers.

Since CC students will often be shy about asking questions, we have found that it works well to sit at a table where the students can walk by and ask questions after the classroom visits are over. All of the CC visits by an ASU team has included a woman and most often also a minority person.

Each semester each rural CC is expected to bring some students to ASU for an Orientation Event. As shown earlier in this paper, 53 students came from these rural schools to visit the METS Center and ASU during Fall 2010. We have learned that if we can visit the campus and talk to students before the ASU visit, more students will be interested and volunteer to come. At Cochise, for example, this fall only three or four students had signed up for the ASU trip when the ASU team came to visit Cochise about two weeks before the trip. As a result of the ASU team visit, eleven students made the three hour trip each way to visit ASU.

The CCs in this project report that the students who visit ASU have come away with a good impression The students felt that the personnel at ASU cared about their progress in the transfer process, like the idea of being part of something before they came, and liked the career advice they received from ASU engineering students and professors. Many of these students had never had anyone to talk to about a career path in engineering, especially to talk to someone who has completed an engineering degree or has worked in the field. This type of inspiration to the 
community college (and high school) students is very important. Career counseling for many of these students has been nonexistent or minimal at best.

\section{Conclusions}

University visitors to community colleges, especially non-metropolitan ones, have a special opportunity to help broaden the vision of young students to include a career in engineering. Growing up in a small town rural setting such as a border town, may have limited a student's career vision to that of a border guard, immigration officer, or a clerk at WalMart. Very few students come into the community college and consider engineering because they have a preconceived idea of what engineering encompasses. University instructor, professor, and student testimonials are invaluable because they provide a view that most $\mathrm{CC}$ students have never envisioned before. The professors and students from ASU who offer to speak one on one with community college students add an element that enlarges the possibilities for perspective students. This type of outreach has a far reaching effect in changing the way students view engineering. Some students at the community college do know what path they are on, but many do not. There is a pervasive perception that because they did not graduate in the top 5\% of their high school class and go off to a university immediately, that engineering is something they cannot do as a career. METS TEP personnel are changing that perception with intrusive advising.

Classroom time in mathematics and science classes can be used as a very effective way of getting students to think about their career and engineering. While trying to interest women and underrepresented minority community college students in engineering, it is helpful to have a woman and a minority on the visiting university team. It is equally important to have women and minority university students interacting with potential transfer students from the community college when they visit the university campus.

\section{References}

1. http://www.nacada.ksu.edu/clearinghouse/advisingissues/intrusive advising.htm Accessed 03/10/2011.

2. http://www.diversityweb.org/diversity innovations/student development/recruitment retention mentoring/ intrusive advising.cfm Accessed 03/10/2011.

3. Anderson-Rowland, M.R., Vanis,M., Guerriero, W., Matar, B.H., Zerby, D.M., Chain, E.L., and Banks, D.L., "Improving the Transition Success of Engineering Community College Students to a University," Proceedings of the American Society for Engineering Education Annual Conference, Port land, Oregon, June 2005, CD-ROM, 16 pages. http://soa.asee.org/paper/conference/paper-view.cfm?id=21561

4. Anderson-Rowland, M.R., "Evaluating an Academic Scholarship Program for Engineering and Computer Science Transfer Students," 36th ASEE/IEEE Frontiers in Education Conference, San Diego, October 2006, 6 pages. http://fie-conference.org/fie 2006/index.html

5. Anderson-Rowland, M.R. and VanIngen-Dunn, C., "Encouraging Transfer Students to Pursue a Bachelor's Degree in Engineering and Computer Science," A merican Society for Engineering Education Annual Conference, Honolulu, HI, June 2007, 7 pages. http://soa.asee.org/paper/conference/paperview.cfm? id=2527

6. Anderson-Rowland, M.R, "An Academic Scholarship Program for Transfer Students in Engineering and Computer Science: A Five Year Su mmary," A merican Society for Engineering Education Annual Conference, Austin, TX, June 2009, 14 pages.

7. Johnson, D. O. and Chen, Y. C., Guaranteed 4.0, JCYC Studio, Dallas, Texas, 2004. 
8. Anderson-Rowland, M.R. and Grierson, A.E., "Evaluating a University/Commun ity College Collaboration for Encouragement of Eng ineering and Computer Science Transfer Students," American Society for Engineering Education Annual Conference, Louis ville, KY, June 2010, 13 pages.

9. Anderson-Rowland, M.R., Rodriguez, A.A., and Grierson, A.E., “ Motivated Engineering Transfers STEM Talent Expansion Program (METSTEP).” A merican Society for Engineering Education Annual Conference, Lou is ville, KY, June 2010, 11 pages.

10. National Acade my of Engineering (NAE), "Changing the Conversation: Messages for Improving Public Understanding of Eng ineering," ISBN: 978-0-309-11934-4. Copyright: 2008. 